Vol. 4, No. 3, March, 2018

\title{
Behavior of Precast Prestressed Concrete Segmental Beams
}

\author{
Mohannad H. Al-Sherrawi ${ }^{a}{ }^{*}$, Abbas A. Allawi ${ }^{a}$, Basim H. AL-Bayati ${ }^{\mathrm{b}}$, \\ Mohanned Al Gharawi ${ }^{\mathrm{c}}$, Ayman El-Zohairy ${ }^{\mathrm{c}}$ \\ ${ }^{a}$ University of Baghdad, Department of Civil Engineering, 10071, Baghdad, Iraq. \\ ${ }^{b}$ Hamorabi State Contracting Contracts Company, 20131, Baghdad, Iraq. \\ ${ }^{c}$ Department of Civil and Environmental Engineering, University of Missouri, Columbia 65211, USA.
}

Received 30 January 2018; Accepted 21 March 2018

\begin{abstract}
The structural behavior of Segmental Precast Post-tensioned Reinforced Concrete (SPPRC) beams largely depends on the behavior of the joints that connect between the segments. In this research, series of static tests were carried out to invest igate the behavior of full-scale SPPRC beams with different types of epoxy-glued joint configurations; multi-key joint, single key, and plain key joint. The reference specimen was monolithically casted beam and the other specimens were segmental beams with five segments for each one. The general theme from the experimental results reflects an approximate similarity in the behavior of the four beams with slight differences. Due to the high tensile strength of the used epoxy in comparison to concrete, cracks at joints occurred in the concrete cover which was attached to the epoxy mortar.
\end{abstract}

Keywords: Concrete Beam; Epoxy Joint; Key Joint; Post-Tensioning; Segmental Beam.

\section{Introduction}

A segmental beam can broadly be defined as that beam which consists of a number of small segments fabricated either in their final position or in some other location, and then assembled to form the beam.

Two methods are commonly used in segmental construction, depending on the particular application. The first method uses cast-in-place concrete, and the second method uses precast concrete units. Pre-tensioning and posttensioning is common practice in the two methods.

The prestressed segmental construction method for reinforced concrete $(\mathrm{RC})$ bridges is rapid, safe, and economical and has been widely used in the construction of long-span RC bridges in different countries around the world.

Joints between adjacent segments can be dry or epoxy-coated, with or without shear keys. The selection of the joint type depends mainly on the prevalent conditions under which the system is to be utilized.

In this research, series of static tests were carried out to investigate the behavior of full-scale Segmental Precast Posttensioned Reinforced Concrete (SPPRC) beams with different types of epoxy-glued joint configurations; multi-key joint, single key, and plain key joint. The reference specimen was a monolithically casted beam and the other specimens were segmental beams with five segments for each one.

\section{Literature Review}

A description of the construction of a post-tensioned segmental beam and a comparison between the experimental

* Corresponding author: dr.Mohannad.Al-Sherrawi@coeng.uobaghdad.edu.iq

doil http://dx.doi.org/10.28991/cej-0309109

$>$ This is an open access article under the CC-BY license (https://creativecommons.org/licenses/by/4.0/).

(C) Authors retain all copyrights. 
structural behaviors with the theoretical calculations were presented by Tito et al. (2011) [1]. The joints were pasted using epoxy, which provided smooth surfaces in addition to sufficient shear strength. Several experimental works have been reported on the SPPRC beams [2-10].

The openings between the segments and crushing of the concrete compression region were the main reasons for the nonlinear behavior of segmental prestressed-concrete beams. Yuan et al. 2015 [6] found that different tendon ratios and different load types increased the external tendon stress and the width of joint openings, and also altered the failure mechanism. Moreover, the segmental beam with prestressed tendons can achieve satisfied flexural capacity and better ductility.

The difference in strength between on-site cast and precast segmental concrete to accurately evaluate the deflection of precast concrete flexural members with joints within the lapped splice had been done by Park et al. 2017 [11].

Creep and shrinkage analyses are considered as an essential part of design and analysis for segmental prestressed beam, because they affect more on loss of prestressing and displacements [12]. A comparison had been made on some concrete creep models to study the creep effect on precast segmental box girder bridge by Xihua et al. 2017 [13]. The influence of the segmental construction technology on the creep calculation also had been discussed.

Finite element analyses for the behavior of segmental concrete beams were presented by some researchers, such as Turmoa et al. 2005; Jiang et al. 2013; and Shamass et al. 2014 [14-16]. In segments with closed joints, shear was transferred along the entire height of the webs. On the other hand, in the case of open joint segments, the shear flow was limited to the compressed zone. The shear capacity predicted by the AASHTO [17] equation diverges from that predicted by numerical analysis at high confining pressure, because the contribution of friction in the total shear capacity decreased with an increase in confining pressure [16].

\section{Experimental Work}

\subsection{Details of Tested Specimens}

In this work, four simply supported post-tensioned RC beams, named as G1, G2, G3 and G4, were tested up to failure. For all tested beams, the overall length was $12000 \mathrm{~mm}$, while the clear span between supports was $11500 \mathrm{~mm}$. The depth and width of the cross-section were $600 \mathrm{~mm}$ and $300 \mathrm{~mm}$, respectively. A schematic presentation of the tested specimens was provided in Figure 1. The first beam, G1, was monolithically casted beam and used as a reference beam. The other beams consisted of five segments joined together with an epoxy paste using different types of joint configuration and each segment with a length of $2400 \mathrm{~mm}$. The beams were reinforced by six longitudinal deformed bars of $12 \mathrm{~mm}$ in diameter as illustrated in Figure 1a. The transverse shear reinforcements were used with a diameter of $10 \mathrm{~mm}$ and a longitudinal spacing of $200 \mathrm{~mm}$ for all beams. As shown in Figure 2, the multi-key joint, plain-key joint and single-key joint were the different joint configurations that used to join the segments for beams G2, G3 and G4, respectively. Epoxy was used as a filling and an adhesive material between segments. The tested beams were post-tensioned with seven wires strands passing through a galvanized duct in concrete. Each strand had an outside diameter of $15.2 \mathrm{~mm}$ and a nominal cross-section of $140 \mathrm{~mm}^{2}$. The initial post-tensioning force was $146 \mathrm{kN}$ (55\% of the tendon ultimate strength). A grout mixture includes cement; water; and non-shrinkage admixture, was pumped with a continuous operation to fill up the galvanized duct and to ensure that all visible slugs of water or inside entrapped air were removed before tightly closing of each outlet. The resulting grout provided excellent corrosion protection for the prestressed tendons and promoted an effective bond between the prestressed tendons and concrete.

\subsection{Materials Properties}

A ready mixed and normal weight concrete was used for all beams. The concrete produced for the purpose of this research consist of ordinary Portland cement Type-I, natural sand with maximum size of $4.75 \mathrm{~mm}$, graded crushed gravel with aggregate maximum size of $19 \mathrm{~mm}$, and ordinary potable water used for concrete mixing and curing. The mixing proportion [cement: fine aggregate: coarse aggregate] was $(1: 1.73: 2.44)$ by weight, and the water-cement ratio was (0.32). This mix was to obtain a target strength average (40 MPa) for cylindrical compressive strength.

Six concrete cylinders of $300 \mathrm{~mm}$ height and $150 \mathrm{~mm}$ in diameter were prepared during the concrete casting for the compressive strength and splitting tensile strength tests. The cylinders and the specimens were cured in the laboratory under a plastic sheet. The average concrete compressive strength, tensile strength and modulus of elasticity achieved after 28 days of curing were 41.3, 4.2 and $3052 \mathrm{MPa}$, respectively. In addition, tension tests of steel reinforcement were also completed according to ASTM A615 [18]. The mechanical properties of the steel reinforcement were listed in Table 1. All tests were conducted at the National Center of Structural Laboratories and Researches in Iraq. The strands, which were used in this experimental work, were made of low relaxation steel with yielding and ultimate strength of 1680 and $1860 \mathrm{MPa}$, respectively. In addition, epoxy of type Concresieve-1406 was used as a filling and an adhesive material between segments. The compressive strength, flexural strength, and bond strength provided by the manufacturer were $75 \mathrm{MPa}, 25 \mathrm{MPa}$ and 3.0 MPa, respectively. 


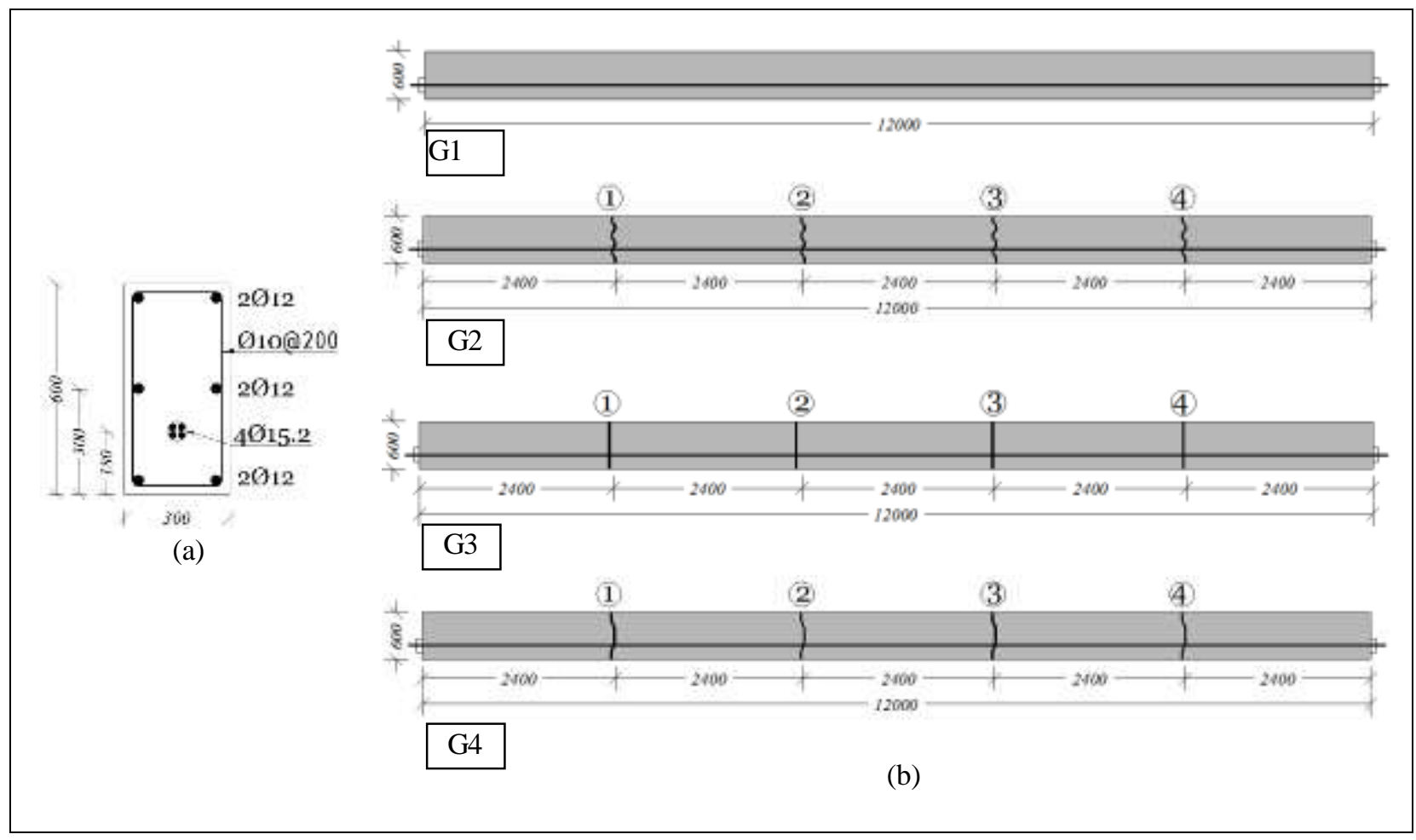

Figure 1. Typical geometry of the tested specimens (dimensions are in mm) (a) cross-section, (b) elevations

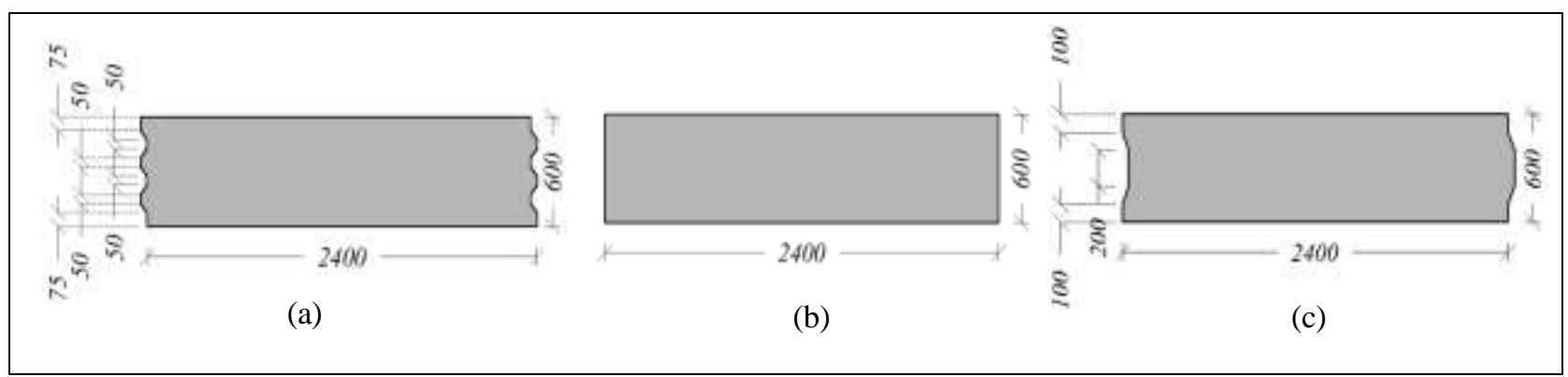

Figure 2. Details of the key-joints (a) multi-key joint, (b) plain-key joint and (c) single-key joint

Table 1. Summary of the materials properties for the steel reinforcement

\begin{tabular}{cccccc}
\hline $\begin{array}{c}\text { Nominal diameter } \\
(\mathbf{m m})\end{array}$ & $\begin{array}{c}\text { Weight } \\
(\mathbf{k g} / \mathbf{m})\end{array}$ & $\begin{array}{c}\mathbf{A}_{\mathbf{s}} \\
\left(\mathbf{m m}^{2}\right)\end{array}$ & $\begin{array}{c}\text { Yield strength } \\
(\mathbf{M P a})\end{array}$ & $\begin{array}{c}\text { Ultimate strength } \\
(\mathbf{M P a})\end{array}$ & $\begin{array}{c}\text { Elongation } \\
(\mathbf{\%})\end{array}$ \\
\hline 10 & 0.60 & 76.9 & 555 & 633 & 13.4 \\
12 & 0.88 & 113 & 557 & 676 & 14.4 \\
\hline
\end{tabular}

\subsection{Instrumentation}

Measurements of strains, deflections and loads were recorded to monitor the behavior of the specimens through the test. Strains were measured in concrete, top and bottom surfaces at midspans, tendons, and transverse reinforcement ties at joint 1 . An incremental encoder was used for measuring deflection at mid-spans of the specimens. This encoder was a digital signal type with a measurement range up to $600 \mathrm{~mm}$. The applied static load was measured using a load cell with a capacity of $2000 \mathrm{kN}$. In addition, a Data Logger was used for collecting the load value, strains and deflection from the testing machine, strain gauges and encoder, respectively.

\subsection{Test Set-Up}

Two $200 \times 150 \times 28 \mathrm{~mm}$ elastomeric bearings were used beneath the ends of each beam to simulate the actual supports of the bridge piers or abutments. The beams were tested under three-point loading as simply supported beams, as illustrated in Figure 3. To avoid any irregularity and to distribute the load uniformly on the top surfaces of concrete, layers of epoxy paste with a thickness of $6 \mathrm{~mm}$ were used at mid-spans under the pressing jack. The loads were applied 
gradually with an incremental rate of $350 \mathrm{~N} / \mathrm{sec}$ (Figure 4). During each test, there were detections and observations for all faces of the specimens by using a wireless microscope with a magnification capacity of 200 times to monitor cracked loads, cracks at joints, and crack patterns.

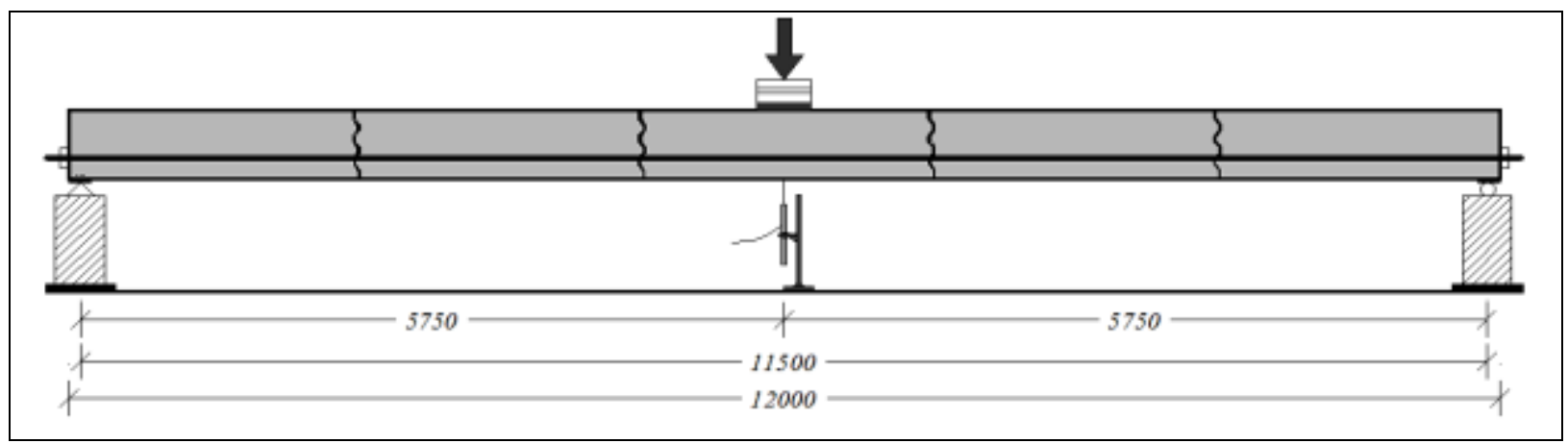

Figure 3. The test set-up (dimensions are in $\mathbf{m m})$

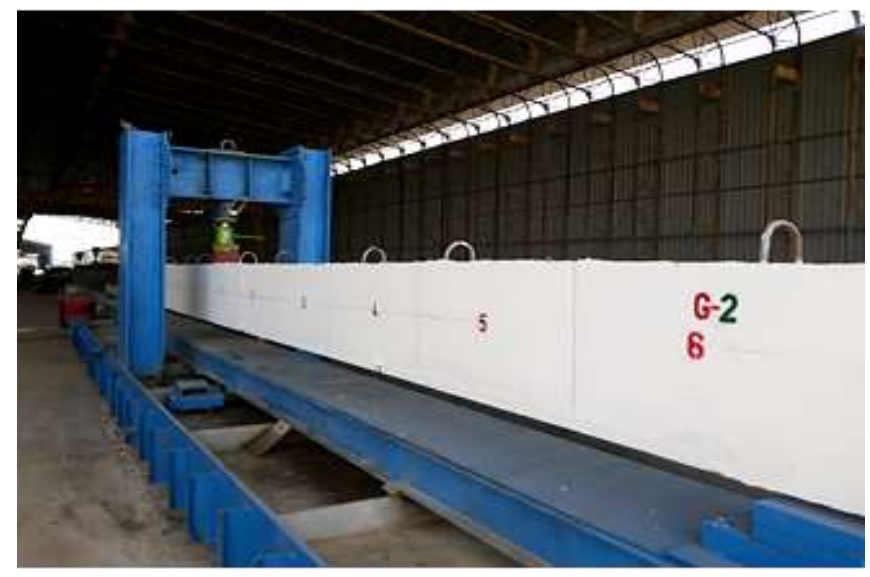

Figure 4. The loading frame

\section{Tests Results}

Table 2 summarizes the basic experimental results of the four configurations tested in this study. The table presented the initial camber at mid-spans due to the effect of the post-tensioning force, cracked and ultimate loads and modes of failure for each beam.

Table 2. Summary of the experimental findings

\begin{tabular}{ccccc}
\hline Beam & $\begin{array}{c}\text { Initial Camber } \\
(\mathbf{m m})\end{array}$ & $\begin{array}{c}\mathbf{P}_{\mathbf{c r}} \\
(\mathbf{k N})\end{array}$ & $\begin{array}{c}\mathbf{P}_{\mathbf{u}} \\
(\mathbf{k N})\end{array}$ & Mode of failure \\
\hline G1 & 10.0 & 46.4 & 172.4 & Tendons failure \\
G2 & 8.5 & 43.9 & 169.5 & Tendons failure \\
G3 & 9.0 & 45.8 & 161.0 & Tendons failure \\
G4 & 9.5 & 40.6 & 166.4 & concrete crushing \\
\hline
\end{tabular}

\subsection{Reference Beam (G1)}

The monolithic beam, G1, was tested to provide reference results for comparison with those of segmental beams. The beam was loaded gradually and hairline cracks at the concrete bottom surface appear when the applied load exceeded the cracked load $(46.4 \mathrm{kN})$. Visible cracking was observed at the bottom surface of the beam as the load increased and these cracks propagated and extended toward the compression zone. The elastic behavior of the beam extends to a load value of $169.7 \mathrm{kN}$ and then intermittent sounds were heard and the pressure gauge readings slightly dropped down. After this loading level, the rate of deflection rapidly increased and a big sound was heard which meant the post-tensioned tendons were broken. The beam exhibited a ductile flexural failure after the tendons' failure due to the presence of the longitudinal reinforcement. Figure 5(a) illustrates the crack pattern for the reference beam and shows 
that the main cracks were concentrated at the middle zone due to the flexural failure. Figure 6(a) shows the failure for the tested beam G1.

\subsection{Segmental Multi-Key Beam (G2)}

The load was applied gradually at mid-span and the first crack was detected at the middle segment between joints 2 and 3 when the load reached $43.9 \mathrm{kN}$. The first crack became wider and propagated by applying more loads. The number and length of cracks increased and transferred to the adjacent segments. The propagation of cracks continued to be increased until an abrupt change in the beam deflection due to a sudden failure in the post-tensioned strands. No cracks were detected in the first and fourth joints as well as in the end segments; as illustrated in Figure 5(b). The ultimate failure load for this beam was $169.5 \mathrm{kN}$ and the ultimate deflection was $206.4 \mathrm{~mm}$. Figure 6 (b) shows the beam G2 at failure.

\subsection{Segmental Plain-Key Beam (G3)}

A different cracking pattern occurred in the case of segments with plain joint type. The first crack was initiated in the concrete covers of the middle segment which were attached to the epoxy mortar for joints 2 and 3 . New cracks were developed within the range of the first segment as the load was increased. All cracks initiated from the lower concrete surface and propagated to pass the centerline of the beam. By adding more loads, more cracks were developed in the adjacent segments; as depicted in Figure 5(c). No cracks were created in the edge segments as well as in joints 1 and 4. The deflection continued to increase until a sudden failure in the post-tensioned strands occurred (Figure 6(c)).

\subsection{Segmental Single-Key Beam (G4)}

The beam remained without any cracks until the applied load reached $40.6 \mathrm{kN}$ then hairline cracks were observed on the bottom surface of the middle segment. As the load was increased, more cracks were created and propagated at the middle segment as well as joints 2 and 3. Furthermore, the gradually increase in loading let the cracks to pass toward the neighbor segments (segments 2 and 4). These cracks were inclined which were known as flexure shear cracks. The cracks were widely opened at joint 2 and flexure shear cracks followed by crushing in concrete occurred at the midspan. During the inspection of joint 2, the post-tensioning force was released and the segments were kept together by the tendons. Due to the discontinuity of the steel reinforcement between segments, a stress concentration, localized cracks, and yielding in the tendons occurred at joint 2 when the load reached the ultimate capacity of the beam. No cracks were detected at the edge segments as illustrated in Figure 5(d). Figure 6(d) shows the beam G4 at failure.

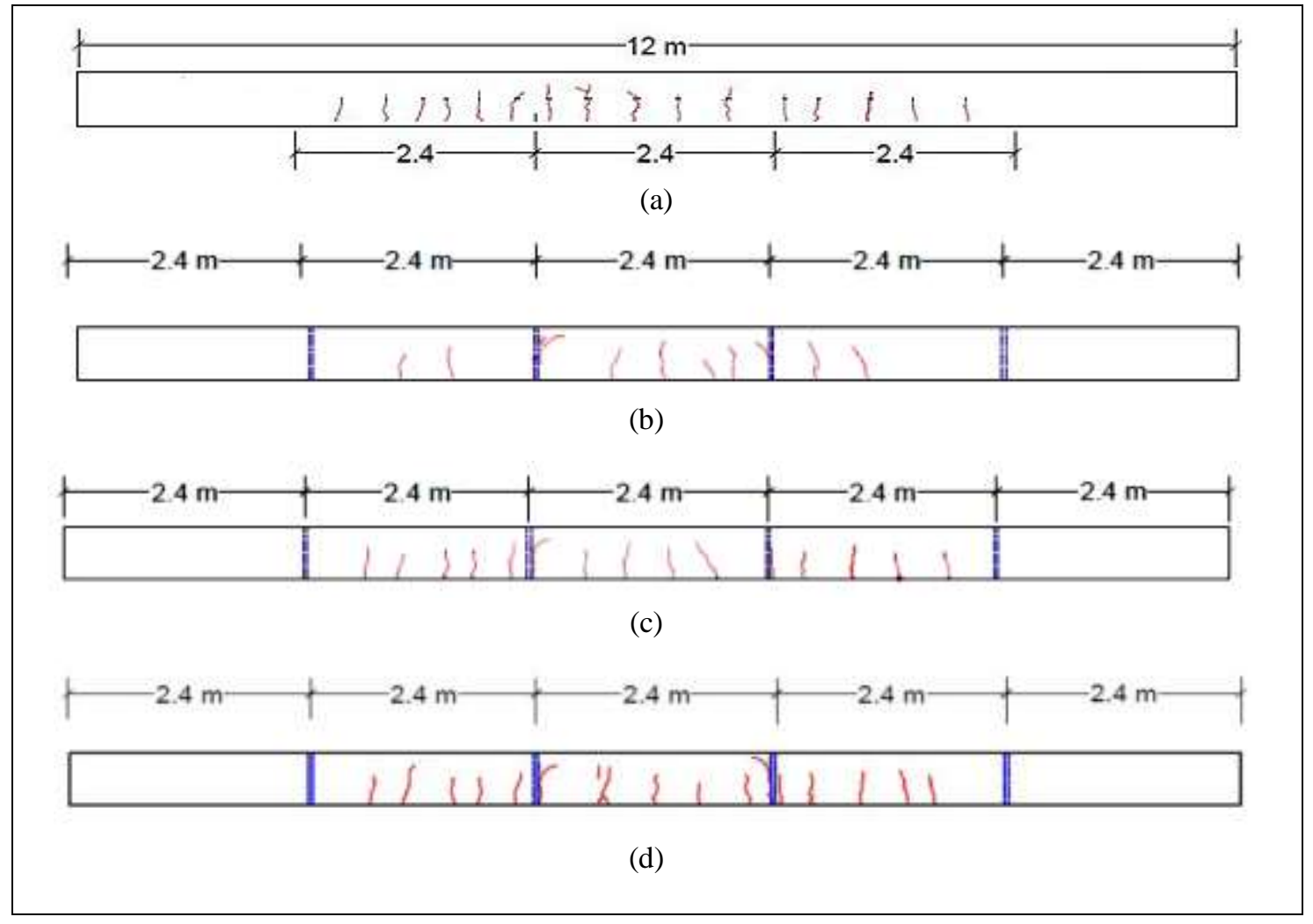

Figure 5. Cracks patterns for the tested beams (a) beam G1; (b) beam G2; (c) beam G3; (d) beam G4 


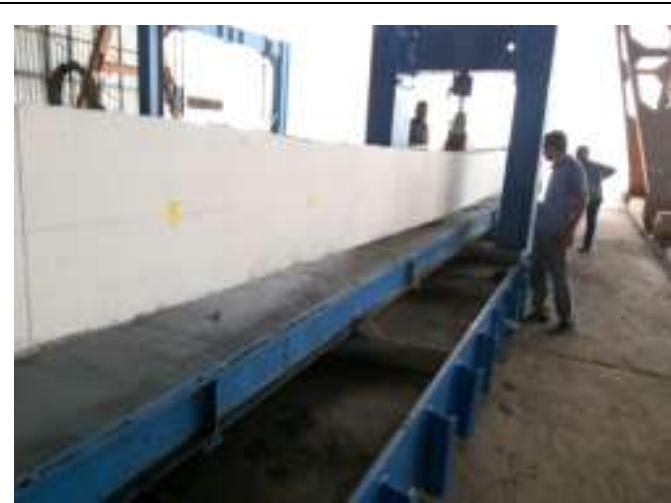

(a)

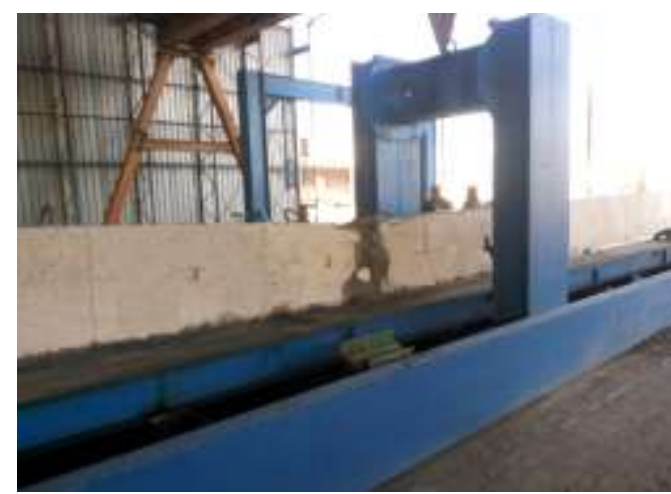

(c)

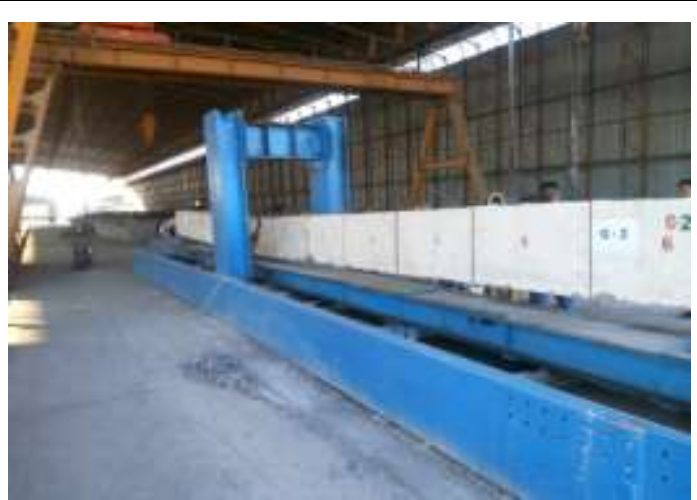

(b)

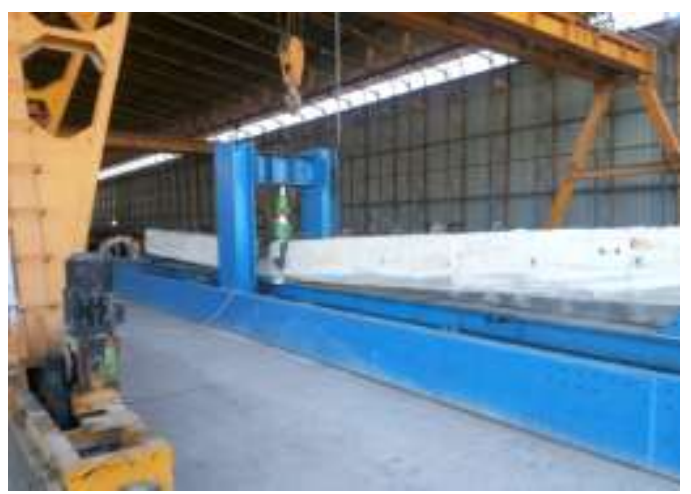

(d)

Figure 6. Failure for the tested beams (a) beam G1; (b) beam G2; (c) beam G3; (d) beam G4

\section{Comparison of Results}

For the segmental beams with different types of joints, it was noticed that the cracks at joints occurred in the interface between the concrete and the epoxy mortar; that can be attributed to the higher tensile strength of the used epoxy in comparison to concrete; as illustrated in Figure 7. Comparisons between the experimental findings for all tested specimens were shown in Figure 8. These comparisons were conducted based on the load-deflection responses, strains in concrete, strains in the post-tensioned tendons and strains in the shear reinforcements.

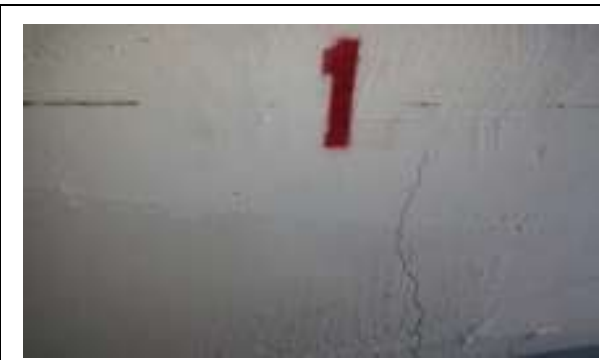

(a)

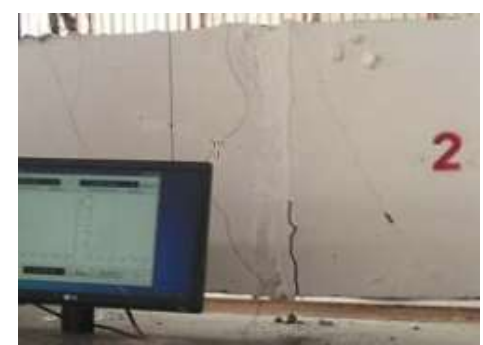

(c)

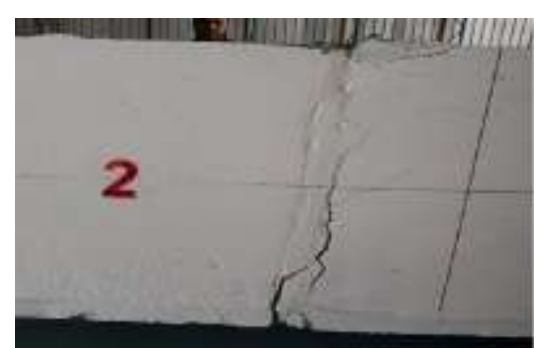

(b)

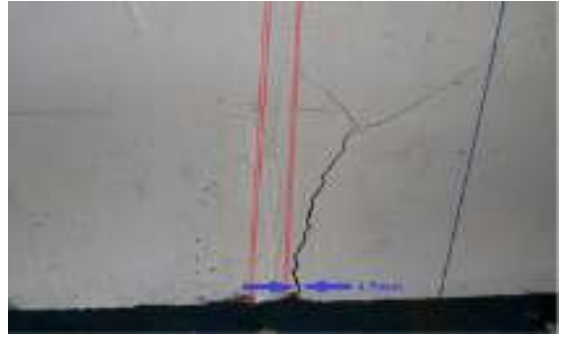

(d)

Figure 7. Cracks in beams (a) reference beam; (b) multi-key joint beam; (c) plain-key joint beam and (d) single-key joint beam 


\subsection{Load Deflection Responses}

The load-deflection relationships, in Figure 8(a), illustrated the initial upward cambers due to the effect of the posttensioning force and the downward deflections due to the service loads at mid-spans of the tested beams. Initially, all the tested beams had the same flexural stiffness because of the un-cracked concrete behavior. With further loading, the cracks at mid-spans caused a reduction in the beam flexural stiffness. The general theme which was abstracted from the experimental results reflected an approximate similarity in the behavior of the four types of beams with slight differences. The ultimate load for the reference beam was $172.4 \mathrm{kN}$ with a difference of $1.7 \%, 6.6 \%$ and $3.5 \%$ in comparison to the segmental beams with multi-keys, plain-key, and one-key joint, respectively.

\subsection{Strain Measurements}

Two strain gauges at each leg of the stirrup at joint 1 were glued and the average reading was obtained. Figure 8(b) illustrated the obtained measurements of each pair of strain gauges at joint 1 . Based on these values of strains, the shear reinforcement was far from yielding. In addition, the strain readings for the reference beam showed fewer values in comparison to the other segmental beams because the continuity of concrete helped to share a part of the shear stresses.

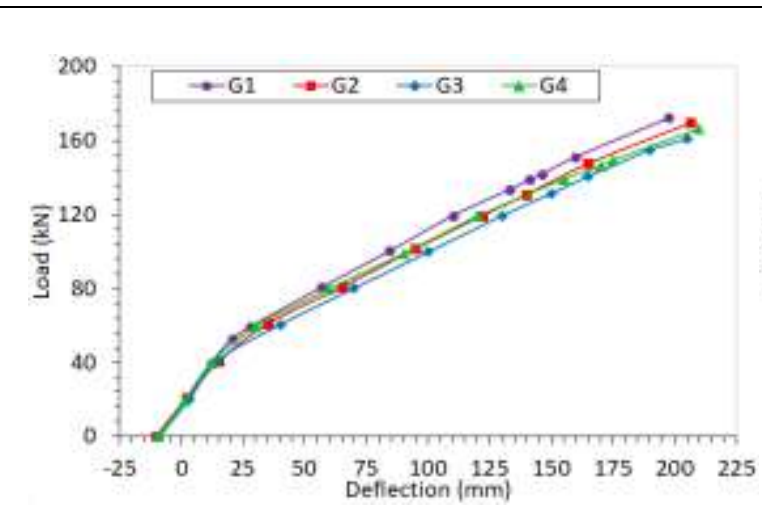

(a)

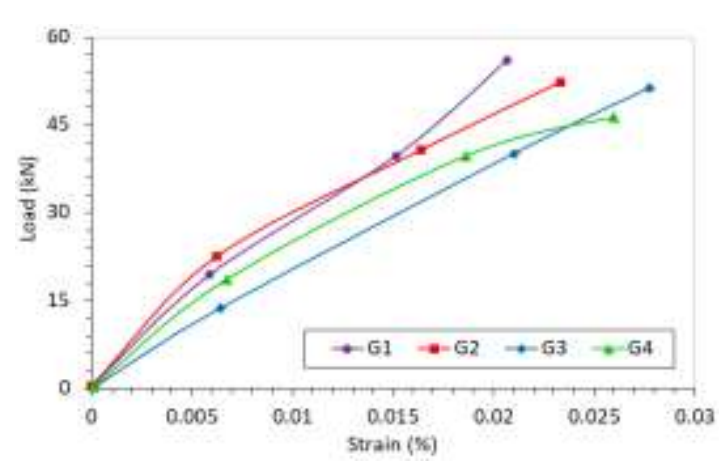

(c)

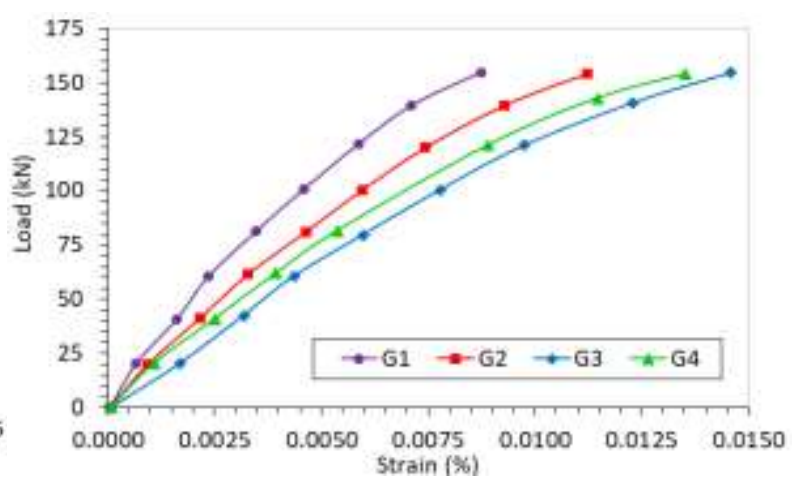

(b)

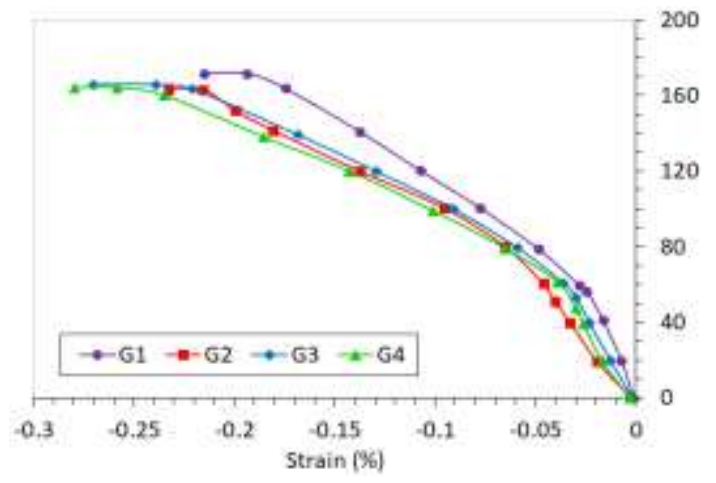

(d)

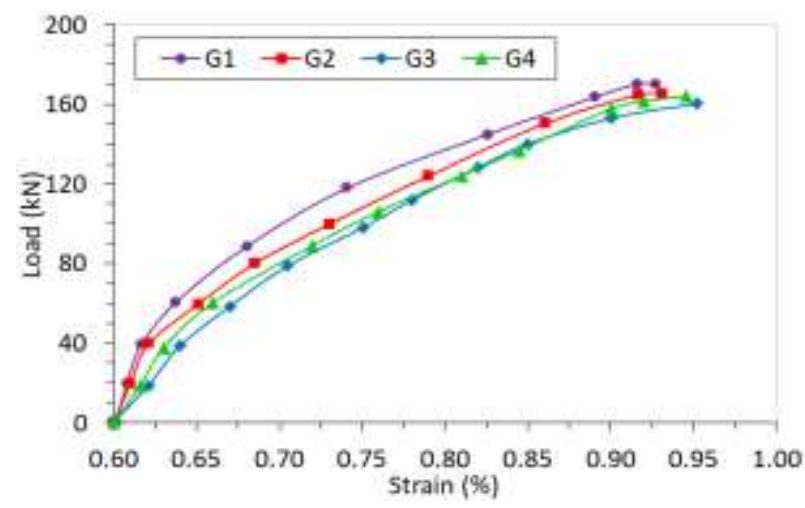

(e)

Figure 8. Experimental findings (a) deflection at mid-spans; (b) strain in stirrups at joint 1; (c) strain in concrete (bottomsurface); (d) strain in concrete (top surface) and (e) strain in tendons 
Figure 8 (c and d) showed strains in concrete at mid-spans of the tested beams. The positive strain values represented a tensile strain on the bottom surface of concrete. Some of strain gauges on the bottom surface of concrete might have been at locations where concrete cracks formed. Therefore, the results of these strain gauges were stopped before reaching the ultimate capacities of the beams. In contrast, the negative strain values indicated a compressive strain on the top surface of concrete. Each curve of strains on the top surface involved three regions with two turning points. The first turning point designated the initial cracks in concrete. The second turning point indicated yielding in the steel reinforcement or the post-tensioned tendons.

The average initial elongations for the post-tensioned tendons in the monolithic beam was 83 mm whereas the elongations were 79.5, 80.75 and $80 \mathrm{~mm}$ in beams with multi-key joint, plain-key joint and one-key joint, respectively. These values of elongations were used to calculate the initial strains in the tendons by dividing the elongations with the original lengths. The strains were recorded by strain gauges during the tests. Therefore, the total strains in the posttensioned tendons at any stage of loading were equal to the initial strains caused by the initial post-tensioning force plus the change in the strains due to the service loads; as illustrated in Figure 8(e).

\section{Conclusion}

Series of static tests were carried out to investigate the behavior of full-scale SPPRC beams with different types of joint configuration; multi-key joint, single-key and plain-key joint. The main conclusions were:

- The general theme that was abstracted from the experimental results reflected an approximate similarity in the behavior of the four types of beams with slight differences.

- The percentage of change in the ultimate load of the segmental beams as compared to the corresponded value of the monolithic beam was in the range of $1.7 \%$ to $6.6 \%$. The lower bound of this range corresponded to the beam with multi-key joints, while the upper bound corresponded to the beam with plain-key joints.

- In the segmental beams with different types of joints, it was noticed that the cracks at the joints occurred in the concrete covers attached to the epoxy mortar which can be attributed to the higher tensile strength of the used epoxy in comparison to concrete.

- The strain readings in the shear reinforcement for the reference beam showed fewer values in comparison to the other segmental beams. The main reason for that was the continuity of concrete helped to share a part of the shear stresses.

\section{References}

[1] Tito, J. A. and Gomez-Rivas, A. "Design, Construction, and Test of a Posttensioned Segmental Beam.” Ninth LACCEI Latin American and Caribbean Conference (LACCEI'2011), Medellín, Colombia. (August 2011).

[2] Saibabu, S., Srinivas, V., Sasmal, S., Lakshmanan, N., and Iyer, N. "Performance Evaluation of Dry and Epoxy Jointed Segmental Prestressed Box Girders under Monotonic and Cyclic Loading." Construction and Building Materials, 38 (Jan. 2013) 931-940. doi.org/10.1016/j.conbuildmat.2012.09.068.

[3] Yuan, A., Dai, H., Sun, D., and Cai, J. "Behaviors of Segmental Concrete Box Beams with Internal Tendons and External Tendons under Bending.” Eng. Struct., 48 (Mar. 2013) 623-634. doi.org/10.1016/j.engstruct.2012.09.005.

[4] Li, G., Yang, D., and Lei, Y. "Combined Shear and Bending Behavior of Joints in Precast Concrete Segmental Beams with External Tendons.” J. Bridge Eng., 18(10) (Oct. 2013) 1042-1052. doi:10.1061/(ASCE)BE.1943-5592.0000453.

[5] Brenkus, N. R. and Hamilton, H. R. "Long Spans with Transportable Precast Prestressed Girders." University of Florida, Department of Civil and Coastal Engineering, (2013).

[6] Yuan, A., He, Y., Dai, H., and Cheng, L. "Experimental Study of Precast Segmental Bridge Box Beams with External Unbonded and Internal Bonded Posttensioning under Monotonic Vertical Loading.” J. Bridge Eng., 20(4) (Apr. 2015) 04014075. doi: $10.1061 /($ asce)be.1943-5592.0000663.

[7] Yuan, A., Wu, W., Sun, D., and Dai, H. "Experimental on Flexural Behavior of Segmental Precast Concrete Beam with Internal Tendons and External Tendons.” Journal of Chang'an University (Natural Science Edition) 35(5), (Sep. 2015) 73-81.

[8] Yuan, A., He, Y., Dai, H., and Sun, D. "Force Bearing Performance Test of Precast Segmental Bridge Beams with Different Tendon Ratios under Different Loads.” Journal of Chang' an University (Natural Science Edition) 36(1), (Jan. 2016) 58-68.

[9] Jiang, H., Cao, Q., Liu, A., Wang, T., and Qiu, Y. "Flexural behavior of precast concrete segmental beams with hybrid tendons and dry joints." Constr. and Building Materials 110 (May 2016) 1-7. doi:10.1016/j.conbuildmat.2016.02.003.

[10] Yang, D. and Yi, T. "Combined Shear and Bending Behavior of Joints in Precast Concrete Segmental Beams with External Tendons ACEM16 Structures16 (Korea 2016).

[11] Park, J., Choi, J., Jang, Y., Park, S.-K., and Hong, S., “An Experimental and Analytical Study on the Deflection Behavior of Precast Concrete Beams with Joints.” Appl. Sci. 7(11), (Nov. 2017), 1198. doi:10.3390/app7111198. 
[12] Wang, S. and Fu, C. C. "Simplification of Creep and Shrinkage Analysis of Segmental Bridges.” J. Bridge Eng., 20(8) (Aug. 2015) B6014001. doi: 10.1061/(asce)be.1943-5592.0000728.

[13] Xihua, D., Liangfang, L., and Rong, X. “Creep Behavior of Precast Segmental Box Girder Bridge.” IOP Conf. Series: Earth and Environmental Science 81 (2017) 012138. doi:10.1088/1755-1315/81/1/012138.

[14] Turmoa, J., Ramosb, G., and Apariciob, A. C. "FEM study on the structural behaviour of segmental concrete bridges with unbonded prestressing and dry joints: Simply supported bridges.” Eng. Struct. 27 (Sep. 2005) 1652-1661. doi:10.1016/j.engstruct.2005.04.011.

[15] Jiang, H., Deng, Y., Qiu, Y., Wei, C., Chen, L., and Feng, W. "Numerical Analysis of Mechanical Properties of Precast Se gmental Concrete Test Beam with External Tendons." Advanced Materials Research 639-640 (Jan. 2013) 460-469. doi.org/10.4028/www.scientific.net/AMR.639-640.460.

[16] Shamass, R., Zhou, X., and Alfano, G. "Finite-Element Analysis of Shear-Off Failure of Keyed Dry Joints in Precast Concrete Segmental Bridges.” J. Bridge Eng., 20(6) (Jun. 2014) 04014084. doi:10.1061/(asce)be.1943-5592.0000669

[17] AASHTO LRFD Bridge Design Specifications. American Association of State Highway and Transportation Officials (AASHTO), 8th Edition, Washington, D.C. (2017).

[18] ASTM A615 / A615M-16, (2016). "Standard Specification for Deformed and Plain Carbon-Steel Bars for Concrete Reinforcement.” ASTM International, West Conshohocken, PA. doi:10.1520/a0615_a0615m-16. 